\title{
Synthesis of Spatially Correlated Earthquake Ground Motions Based on Hilbert Transform
}

\author{
Erlei Yao, ${ }^{1}$ Yu Miao, ${ }^{1}$ and Guobo Wang ${ }^{2}$ \\ ${ }^{1}$ School of Civil Engineering and Mechanics, Huazhong University of Science and Technology, Wuhan 430074, China \\ ${ }^{2}$ Hubei Key Laboratory of Roadway Bridge \& Structure Engineer, Wuhan University of Technology, Wuhan 430074, China \\ Correspondence should be addressed to Yu Miao; miaoyu@hust.edu.cn
}

Received 14 March 2017; Accepted 4 June 2017; Published 6 July 2017

Academic Editor: Hongyi Li

Copyright (C) 2017 Erlei Yao et al. This is an open access article distributed under the Creative Commons Attribution License, which permits unrestricted use, distribution, and reproduction in any medium, provided the original work is properly cited.

A simplified method for synthesizing spatially correlated earthquake ground motions is developed based on Hilbert transform and a reference earthquake record. In this method, one reference earthquake record is treated as the original ground motion, based on a series of generated ground motions. This procedure uses the instantaneous amplitude and the instantaneous phase of the record obtained using Hilbert transform to achieve the nonstationarity of ground motion. To establish the coherency between generated ground motions, an incoherence model is employed to describe the relation between the instantaneous phase at the present station and the instantaneous phases at previous stations. This type of phase is defined as the instantaneous coherence phase. In addition, time lag is included in the instantaneous coherence phase to prescribe the wave passage effect. The proposed Hilbert-transformbased method is efficient and avoids cumbersome parameter estimations as well as other drawbacks involved in some traditional synthesizing methods. Applications of this method demonstrate that the generated ground motions are statistically analogous with the reference record.

\section{Introduction}

In the past decades, the methods of generating spatially variable ground motions were studied thoroughly. A number of studies demonstrate that the effect of spatially variable ground motions on the responses of long structures is not negligible [1-7]. Nowadays, the synthesizing methods [811] based on stochastic process theory are popular and are implemented as a tool in most of the finite-element packages [12]. Stochastic procedures usually include power spectral matrix/incoherence matrix decomposition $[13,14]$ or spectral factorization [15], which involves massive calculation, thus decreasing the synthesizing efficiency. In addition, the nonstationarity of ground motion is a significant factor in the process of generating ground motions, which includes intensity nonstationarity and frequency nonstationarity [16]. Intensity nonstationarity is usually achieved by multiplying the generated stationary process using an envelope function. However, this method may not be applicable for simulations based on a recorded accelerogram, because the applied envelop function may not completely present the intensity nonstationarity of the original ground motion. Moreover, studies by Ohsaki [17] showed that the seismic waveform was governed by the distribution of the phase difference spectrum; thus, phase difference spectrum could be used to achieve intensity nonstationarity. Zhu and Feng [18, 19] studied the distribution characteristic of the phase difference spectrum and proposed a method of generating a random phase. This method can achieve full nonstationarity; however, the effect of the randomness of the generated phase on the ground motions is not confirmed. Several methods have been proposed for frequency nonstationarity [20-26]. These methods involve complex processes and massive calculation. Conditional simulation is an alternative and several contributions have been made to the study of ground motion simulation $[27,28]$.

In the present paper, a simplified conditional simulation method of synthesizing spatially correlated earthquake ground motions is proposed based on Hilbert transform and earthquake record. In this method, one reference earthquake record is treated as the original ground motion, based on which a series of ground motions are generated. By 
performing Hilbert transform on the known earthquake record, the instantaneous amplitude and the instantaneous phase of the earthquake record can be obtained. The instantaneous amplitude is utilized as an envelope function to achieve the intensity nonstationarity of each simulated ground motion. To establish the coherency between generated ground motions, a coherence model is employed to describe the relation between the instantaneous phase at the present station and the instantaneous phases at previous stations. The instantaneous coherence phases at different stations are all statistically analogous with that of the known record. Thus every generated ground motion can present similar frequency nonstationarity. This type of phase is defined as an instantaneous coherence phase. In addition, time lag is included in the instantaneous coherence phase to prescribe the wave passage effect. The proposed Hilbert-transformbased method can efficiently achieve intensity nonstationarity and frequency nonstationarity, and this approach avoids cumbersome parameter estimations, as well as other drawbacks involved in some traditional synthesizing methods. The application of this method demonstrates its validity and practical value.

\section{Hilbert Transform}

For a real-valued function $x(t)$, its Hilbert transform $y(t)$ is defined as

$$
y(t)=H[x(t)]=\frac{1}{\pi} P \int_{-\infty}^{\infty} \frac{x(\tau)}{t-\tau} d \tau,
$$

where $P$ denotes the Cauchy principal value of the integral. Thus, by using the Hilbert transform, an analytic signal $z(t)$ which is a complex-valued function can be obtained as follows [29]:

$$
z(t)=x(t)+i y(t)
$$

which can be further expressed as

$$
z(t)=a(t) e^{i \theta(t)}
$$

where $i^{2}=-1$.

$$
\begin{aligned}
& a(t)=\sqrt{x^{2}(t)+y^{2}(t)} \\
& \theta(t)=\arctan \frac{y(t)}{x(t)} .
\end{aligned}
$$

Thus, the original function $x(t)$ can be expressed as

$$
x(t)=a(t) \cos [\theta(t)],
$$

where the independent variable $t$ denotes time and time functions $a(t)$ and $\theta(t)$ are called the instantaneous amplitude and the instantaneous phase function or, by Bendat and Piersol [30], the envelop signal and the instantaneous phase signal of $x(t)$, respectively. In addition, $a(t)$ represents the amplitude modulation, and $\cos [\theta(t)]$ represents the frequency modulation mechanisms contained in the original signal and $\theta(t)$ is between $-\pi$ and $\pi$. In other words, $a(t)$ governs the intensity nonstationarity (or the temporal variation of amplitude), whereas $\theta(t)$ dominates the frequency nonstationarity (or the temporal variation of frequency content) of the signal $x(t)$.

\section{Proposed Method}

In this study, the spatial variation of ground motion is prescribed in terms of wave scattering as well as wave passage effects. The soil condition and geology of the field of interest were assumed to be uniform. The well-known north-south component of the natural ground motion recorded at the El Centro station during the 1940 earthquake in Imperial Valley, California, which had a magnitude of $6.95 \mathrm{Mw}$, is chosen as the reference accelerogram, as shown in Figure 1(a). The recorded ground motion exhibits a sampling rate of $50 \mathrm{~Hz}$ and the anterior $40.94 \mathrm{~s}$ time history of the record is extracted to be studied with a total of 2048 values. First, the instantaneous amplitude $a(t)$ and the instantaneous phase functions $\theta(t)$ can be obtained by performing the Hilbert transform on the known earthquake record, as indicated in Figures 1(b) and 1(c), respectively. The instantaneous amplitude is treated by the method as an envelop function, with a value that will be preserved into the synthetic samples.

According to (5), the original earthquake ground motion can be expressed, and the acceleration process at station $n$ can be given as

$$
\begin{aligned}
& x_{n}(t) \\
& =a(t) \cos \left[\theta(t)+\sum_{k=0}^{n-1} \arccos \left(\mu_{k, n} \cos \left(\theta_{k}(t)\right)\right)+\tau_{n}\right],
\end{aligned}
$$

where $\tau_{n}$ is the time lag between the two stations given by [13]

$$
\tau_{n}=\frac{\omega \cdot r_{n}}{V}
$$

where $r_{n}$ denotes the separation distance between the two stations projected parallel to the dominant wave propagation direction and is assumed to be $200 \mathrm{~m}$ uniformly; $V$ represents the apparent seismic wave velocity in the medium, which is $500 \mathrm{~m} / \mathrm{s}$; and $\mu_{k, n}$ indicates the coherence function between two instantaneous phases. The instantaneous phase at the present station is assumed to be only affected by these phases at previous stations. Thus, the effect of phases at previous stations on the present phase can be expressed by $\sum_{k=0}^{n-1} \arccos \left(\mu_{k, n} \cos \left(\theta_{k}(t)\right)\right)$. The relevant verification is shown in appendix.

Many coherency models were proposed, such as the models proposed by Loh and Lin [31], Feng and $\mathrm{Hu}$ [32], Loh and Yeh [33], Hao et al. [34], and Harichandran and Vanmarcke [35]. In this study, the Sobczyk model [36] is selected to describe the coherency loss between the ground motions at points $m$ and $n$ as follows:

$$
\mu_{m, n}(i \omega)=\exp \left(-\frac{\beta \omega d_{m, n}^{2}}{V}\right) \cdot \exp \left(-i \omega d_{m, n} \cos \frac{\alpha}{V}\right)
$$

which reflects the level of coherency loss; $\beta=0.0005$ is used in the present paper, which indicates highly correlated motions [37]; $\alpha$ is the incident angle of the incoming wave to the site, and it is assumed to be $0^{\circ}$. 


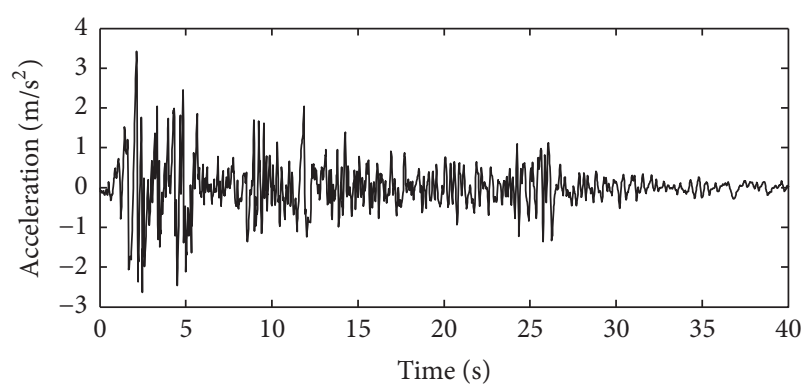

(a)

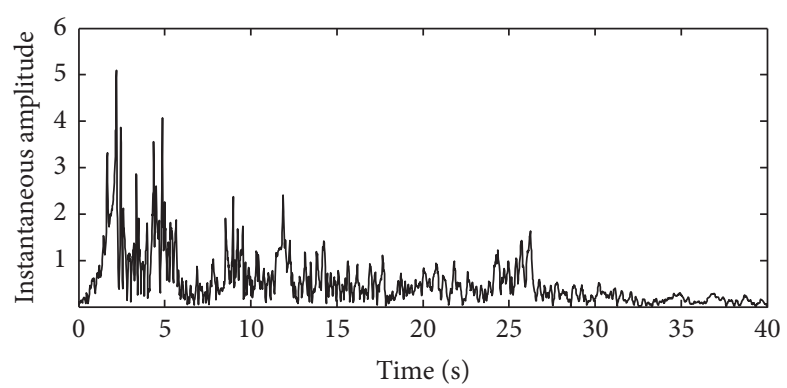

(b)

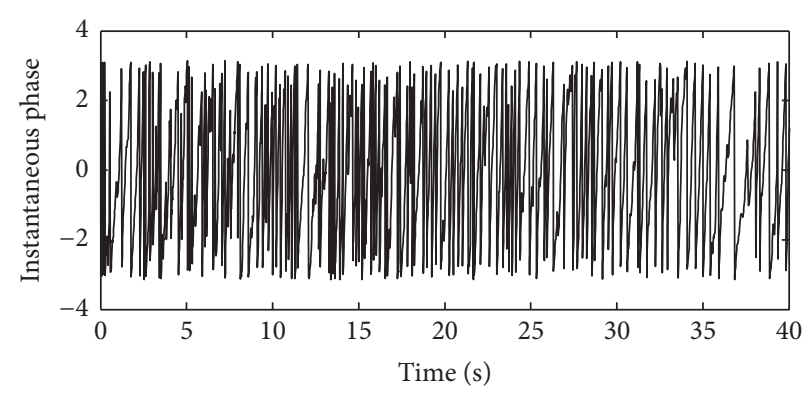

(c)

FIGURE 1: El Centro earthquake record: (a) acceleration; (b) instantaneous amplitude; (c) instantaneous phase angle.

\section{Verification of the Proposed Method}

To verify the proposed method, a set of comparisons are conducted, including comparison of (1) peak ground accelerations (PGA), peak ground velocity (PGV), and peak ground displacement (PGD); (2) Fourier amplitude and response spectra amplitude; and (3) coherence function of simulated motions to those of the known record.

4.1. Comparison of $P G A, P G V$ and $P G D$. A series of accelerograms at three stations arranged at $200 \mathrm{~m}, 400 \mathrm{~m}$, and $600 \mathrm{~m}$ from the original record are simulated using the proposed methodology. The acceleration, velocity, and displacement time histories at each point are presented in Figures 2-4, respectively. The waveform of time histories of acceleration, velocity, and displacement at each point are all consistent with the original record. The PGAs, PGVs, and PGDs of the simulated motions are compared with those of the original ground motion, which are presented in Table 1. The PGA, PGV, and PGD at every station are close to those of the known record. Besides, from those time histories figures, it can be seen that the generated ground motions have the identical intensity nonstationarity and frequency nonstationarity with the original record. These comparison results verify that the simulated ground motions are rational.

4.2. Comparison of Fourier Amplitude and Response Spectra. Figure 5 provides the results of Fourier amplitude of simulated motions compared with those of the original record. Figure 6 presents the response spectra amplitude of simulated motions, as well as that of the original record. The spectral values are close to that of the known record. The
TABLE 1: Peak values of the simulated and recorded ground motions.

\begin{tabular}{lccc}
\hline Station & $\begin{array}{c}\text { Acceleration } \\
\left(\mathrm{m} / \mathrm{s}^{2}\right)\end{array}$ & $\begin{array}{c}\text { Velocity } \\
(\mathrm{m} / \mathrm{s})\end{array}$ & $\begin{array}{c}\text { Displacement } \\
(\mathrm{m})\end{array}$ \\
\hline Recorded motion & 3.417 & 0.335 & 0.109 \\
$r=200 \mathrm{~m}$ & 3.426 & 0.351 & 0.098 \\
$r=400 \mathrm{~m}$ & 3.404 & 0.317 & 0.099 \\
$r=600 \mathrm{~m}$ & 3.804 & 0.342 & 0.085 \\
\hline
\end{tabular}

comparison of the time-frequency spectra of the generated ground motions to that of the known record is shown in Figure 7 . The time-frequency spectra were obtained by using the short time Fourier transform. The figure shows that both spectral amplitude and tendency are similar to that of the known record.

4.3. Comparison of Coherence. Figure 8 indicates the coherency values between the generated time histories and the known record as well as the corresponding Sobczyk model. A good match can also be observed except for $\mu_{0,2}$ and $\mu_{0,3}$ in the high frequency range. However, this result is expected because the cross correlation between the generated motions or their coherency values decrease rapidly with frequency as the separation increases [37]. A previous study [38] indicated that the coherency value of approximately $0.3-0.4$ is the threshold of the cross correlation between two signals because numerical calculations of the coherency function between any two white noise series result in a value of roughly $0.3-0.4$. Thus the calculated coherency function between two simulated time histories is smaller than the target value. 


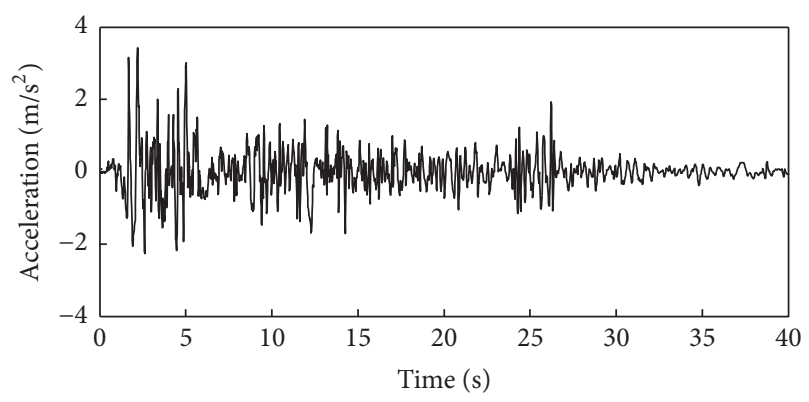

(a)

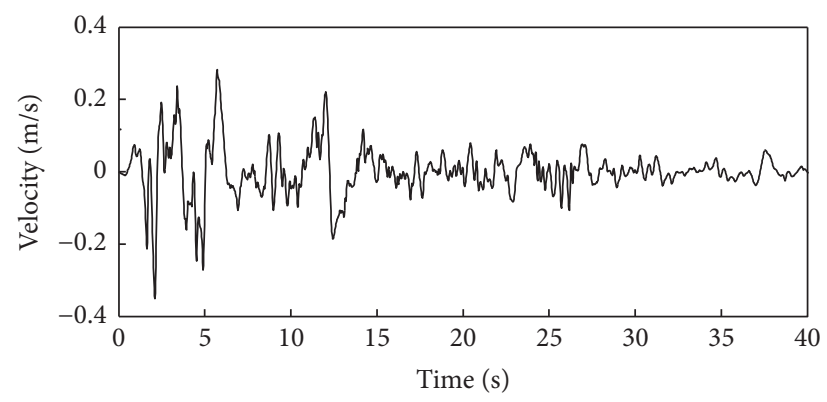

(b)

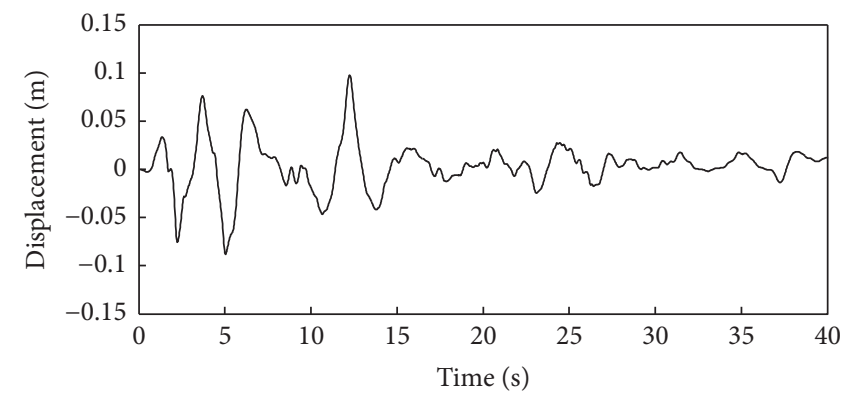

(c)

FIGURE 2: Simulated ground motion at station with $r_{n}=200 \mathrm{~m}$ : (a) acceleration; (b) velocity; (c) displacement.

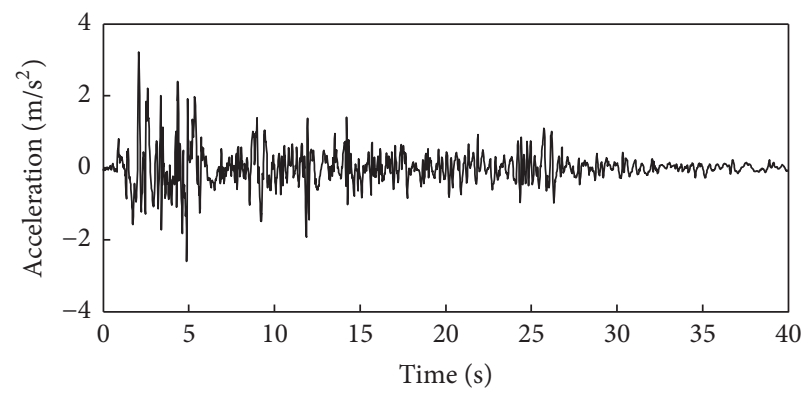

(a)

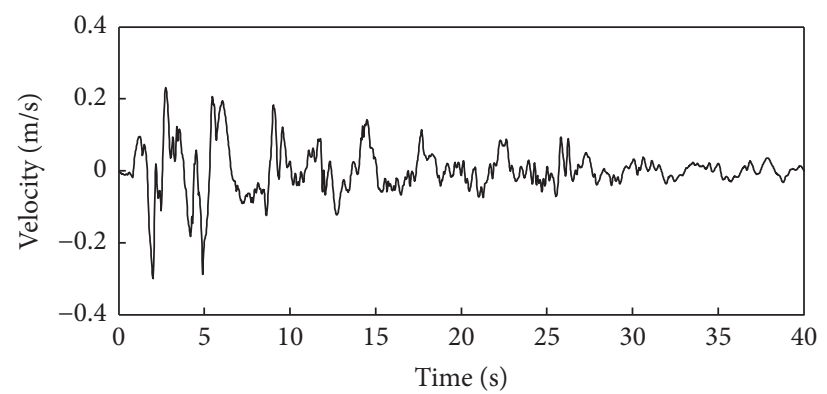

(b)

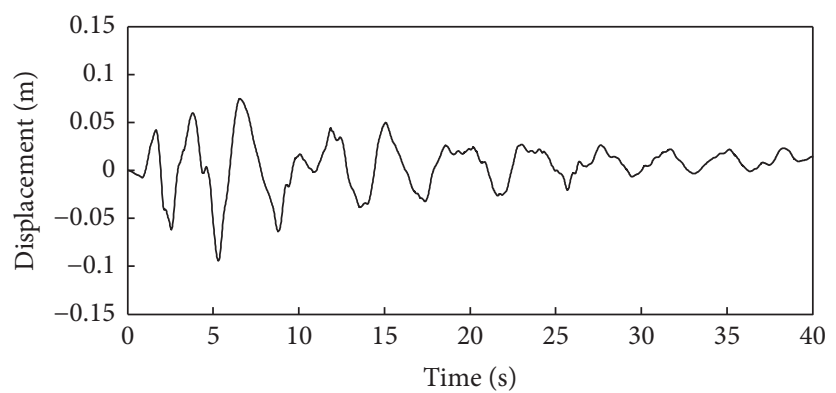

(c)

FIGURE 3: Simulated ground motion at station with $r_{n}=400 \mathrm{~m}$ : (a) acceleration; (b) velocity; (c) displacement.

\section{Conclusion}

In this study, an approach was developed to simulate spatially correlated earthquake ground motions based on Hilbert transform and earthquake records where instantaneous coherence phase is defined. In this method, one recorded accelerogram is treated as the original ground motion, based on which a series of ground motions are generated. By performing Hilbert transform on the known earthquake record, the instantaneous amplitude and the instantaneous phase of the earthquake record can be obtained. The instantaneous amplitude is utilized as an envelop function to achieve the intensity nonstationarity of each simulated ground motion. To establish the coherency between 


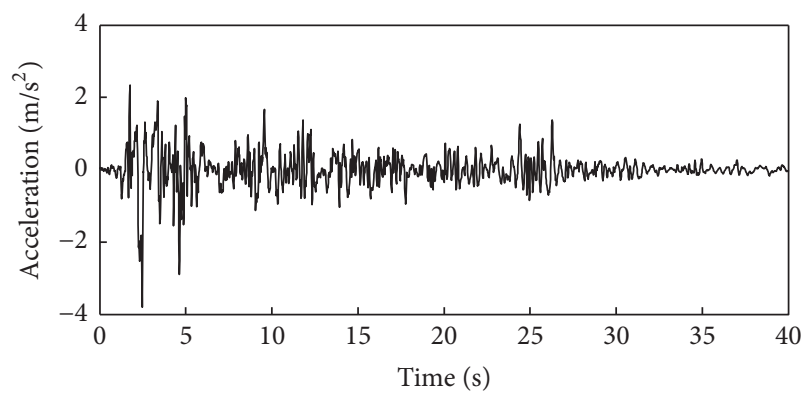

(a)

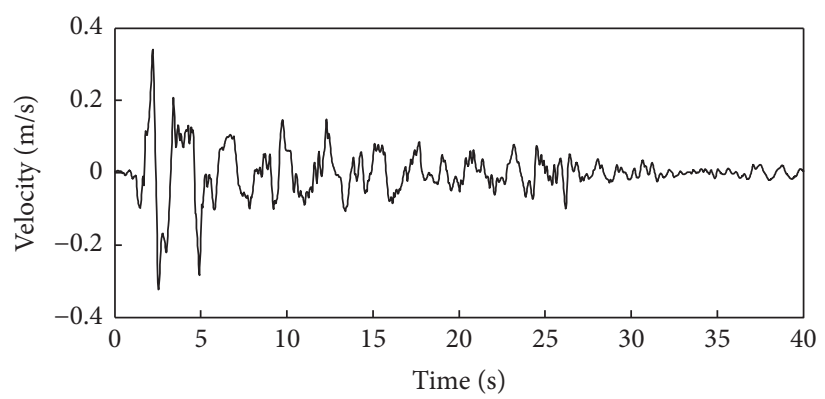

(b)

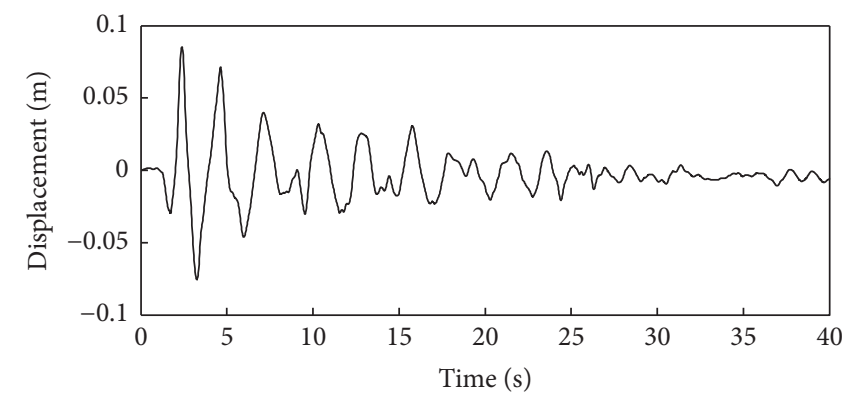

(c)

FIGURE 4: Simulated ground motion at station with $r_{n}=600 \mathrm{~m}$ : (a) acceleration; (b) velocity; (c) displacement.
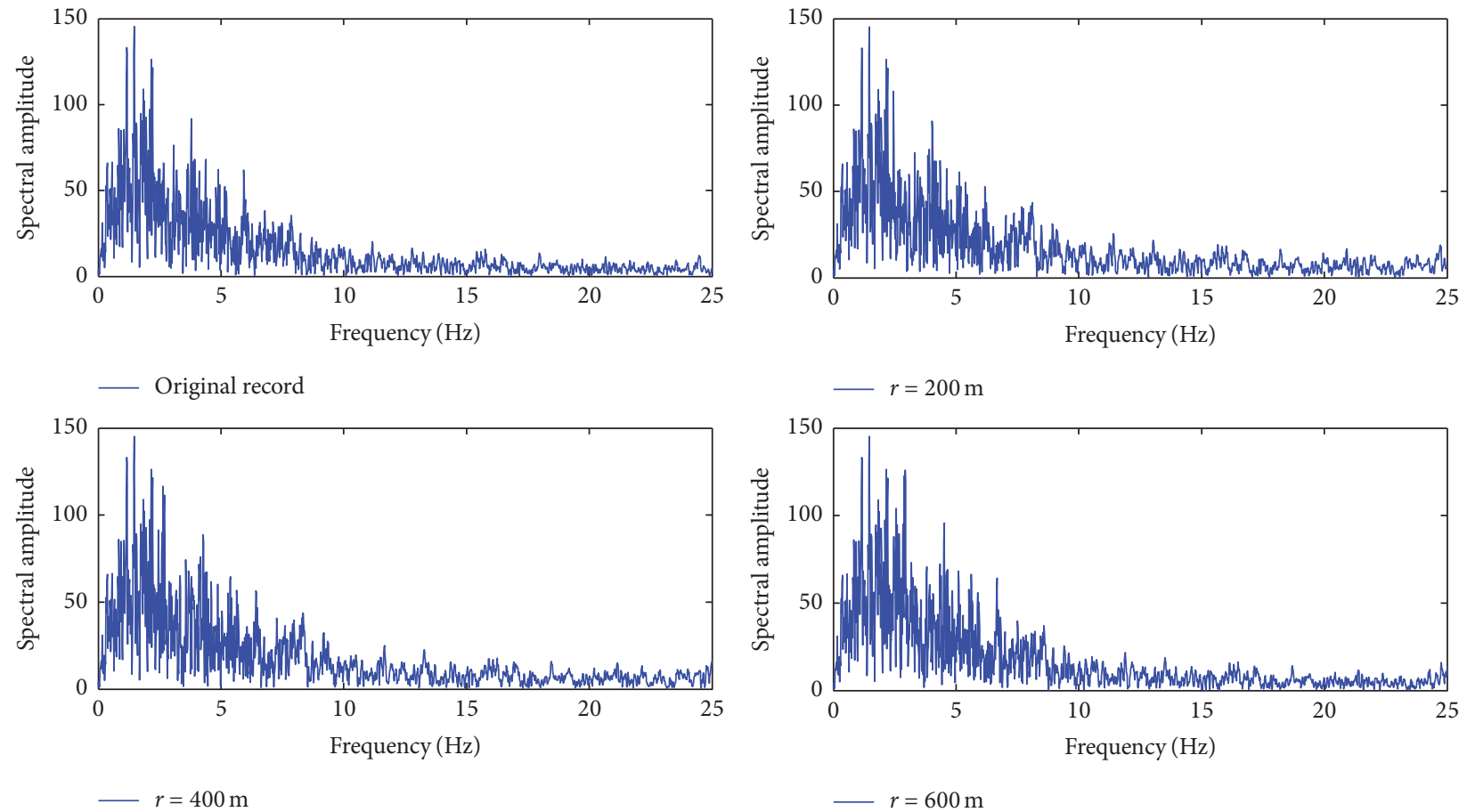

FIgURE 5: Comparison of Fourier amplitude of simulated motions to that of the original record.

generated ground motions, the Sobczyk model is employed in describing the relation between the instantaneous phase at the present station and the instantaneous phases at previous stations. The instantaneous coherence phases at different stations are all statistically analogous with that of the known record. Thus every generated ground motion can present similar frequency nonstationarity. In addition, time lag is included in the instantaneous coherence phase to prescribe the wave passage effect. The proposed Hilbert-transform-based method is concise and avoids many 


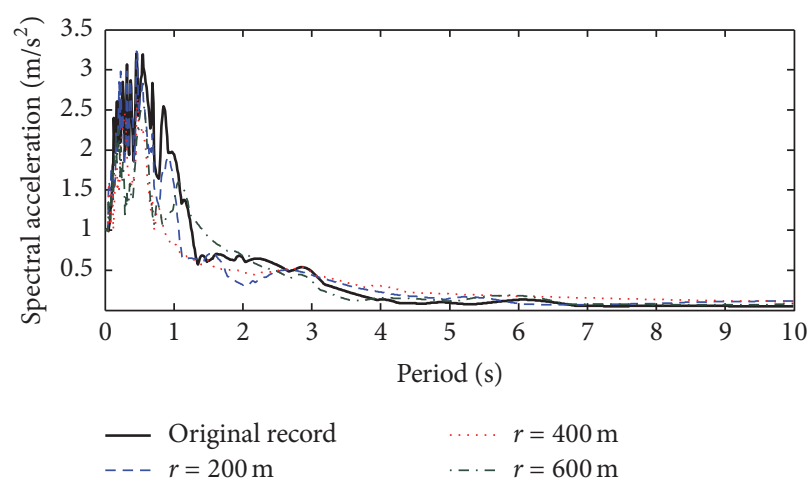

FIGURE 6: Comparison of response spectra with $2 \%$ damping ratio of simulated motions to that of the original record.

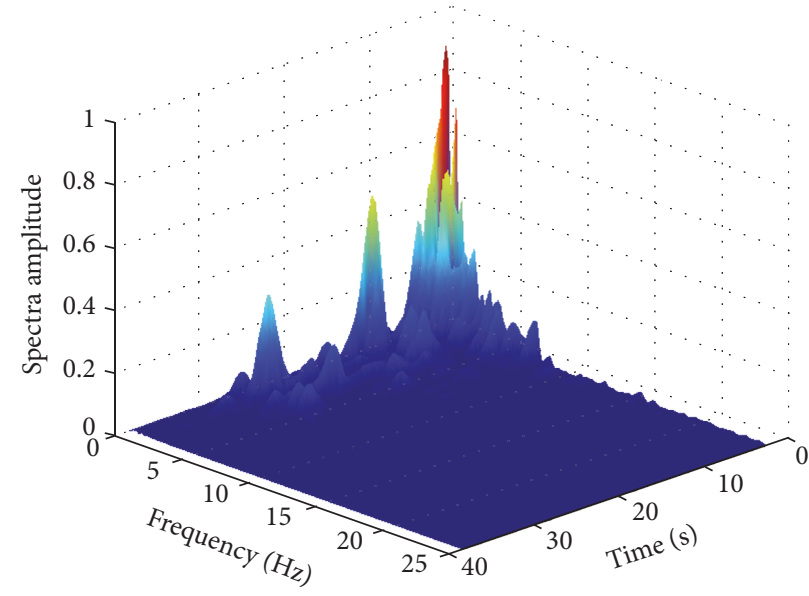

(a)

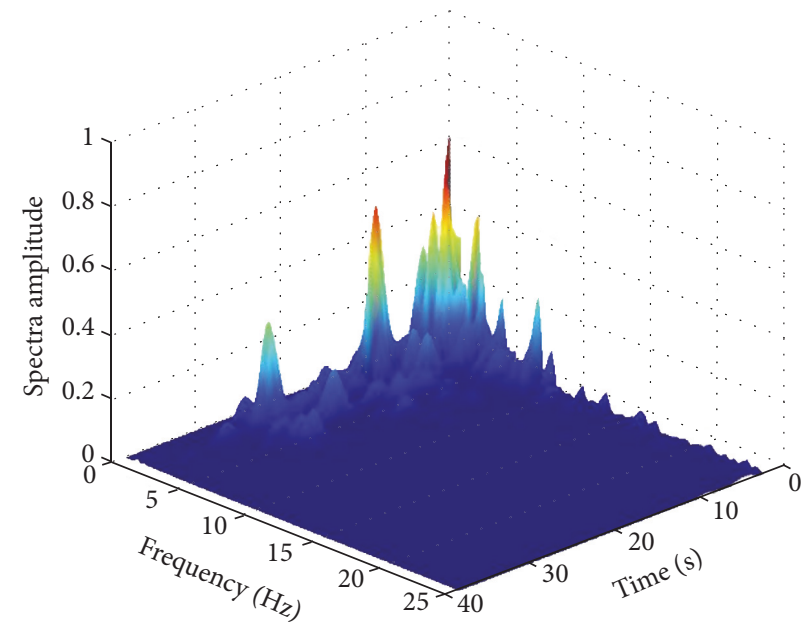

(c)

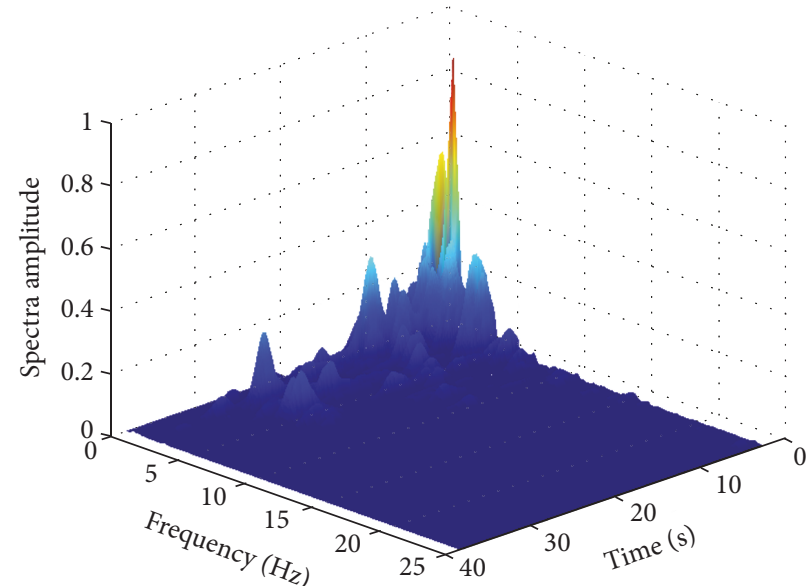

(b)

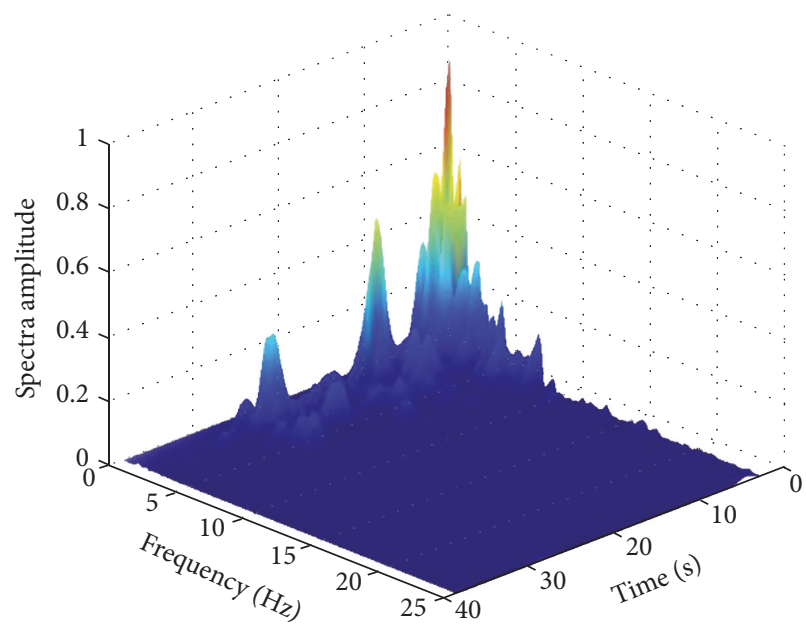

(d)

Figure 7: Comparison of time-frequency spectral at simulated stations to that of the original record: (a) the time-frequency spectrum of the known record; (b), (c), (d) the time-frequency spectrum of 1-3 simulated motion.

drawbacks involved in some traditional synthesizing methods. The power spectra density of every simulation point is considered to be identical in the proposed method, so it is applicable to the relatively small field only. Because for large-scale field, the power spectra density of each simulation point might be different. Thus, it has been considered that the local site effect should be incorporated in the synthesis method in the future. 


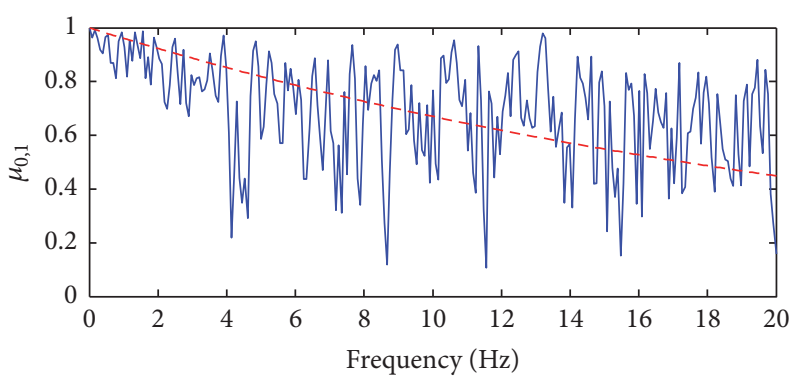

(a)

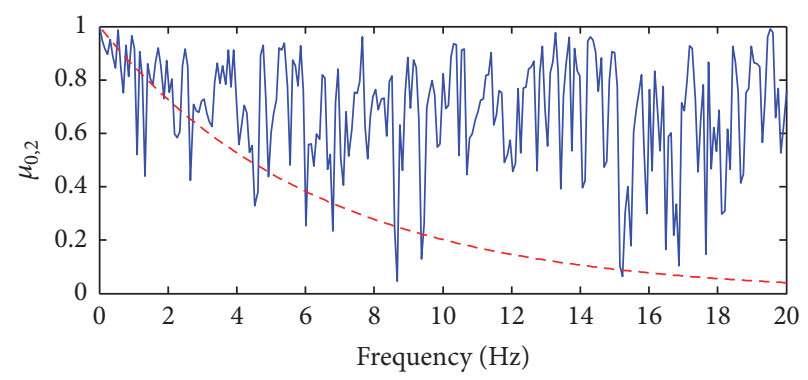

(b)

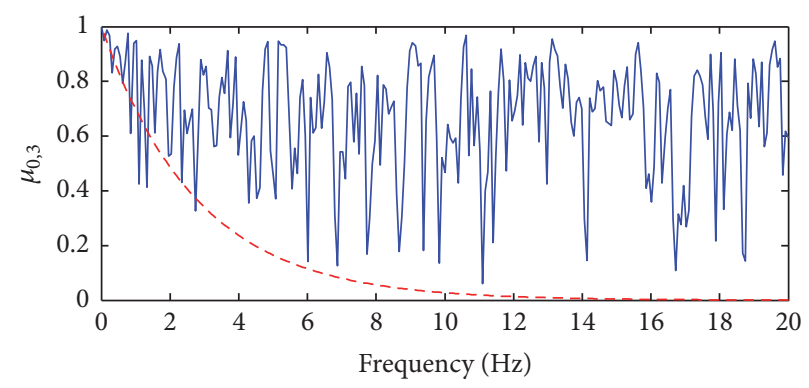

(c)

FIGURE 8: Comparison of coherency loss between the simulated accelerations with target value.

\section{Appendix}

\section{Verification for the Instantaneous Coherency Phase}

As mentioned above, it is assumed that the soil condition and geology of the field of interest were uniform, so the power spectra density at each point is uniform and the coherency function between $m$ th and $n$th point can be given as follows:

$$
\mu_{m, n}(\omega)=\frac{S_{m n}(\omega)}{\sqrt{S_{n n}(\omega) S_{m m}(\omega)}}=\frac{S_{m n}(\omega)}{S_{n n}(\omega)}
$$

$$
\mu_{m, n}(\omega)=\frac{\int_{-\infty}^{\infty}\left[\int_{-\infty}^{\infty} x_{m}(t) x_{n}(t-\tau) d t\right] e^{-i \omega \tau} d \tau}{\int_{-\infty}^{\infty}\left[\int_{-\infty}^{\infty} x_{m}(t) x_{m}(t-\tau) d t\right] e^{-i \omega \tau} d \tau}
$$

where $\tau$ denotes a time lag. By using Hilbert transform, $x_{m}(t)$ and $x_{n}(t)$ can be expressed as

$$
\begin{aligned}
x_{m}(t) & =a_{0}(t) \cos \left[\theta_{m}(t)\right] \\
x_{n}(t) & =a_{0}(t) \cos \left[\theta_{n}(t)\right] .
\end{aligned}
$$

Substituting (A.3) into (A.2), $\mu_{m, n}(\omega)$ can be expressed as

$$
\mu_{m, n}(\omega)=\frac{\int_{-\infty}^{\infty}\left[\int_{-\infty}^{\infty} a_{0}(t) a_{0}(t-\tau) \cos \left[\theta_{m}(t)\right] \cos \left[\theta_{n}(t-\tau)\right] d t\right] e^{-i \omega \tau} d \tau}{\int_{-\infty}^{\infty}\left[\int_{-\infty}^{\infty} a_{0}(t) a_{0}(t-\tau) \cos \left[\theta_{m}(t)\right] \cos \left[\theta_{m}(t-\tau)\right] d t\right] e^{-i \omega \tau} d \tau}
$$

and then

$$
\begin{aligned}
& \mu_{m, n}(\omega) \int_{-\infty}^{\infty}\left[\int_{-\infty}^{\infty} a_{0}(t) a_{0}(t-\tau) \cos \left[\theta_{m}(t)\right]\right. \\
& \left.\cdot \cos \left[\theta_{m}(t-\tau)\right] d t\right] e^{-i \omega \tau} d \tau=\int_{-\infty}^{\infty}\left[\int_{-\infty}^{\infty} a_{0}(t)\right. \\
& \left.\cdot a_{0}(t-\tau) \cos \left[\theta_{m}(t)\right] \cos \left[\theta_{n}(t-\tau)\right] d t\right] e^{-i \omega \tau} d \tau \\
& \int_{-\infty}^{\infty} \int_{-\infty}^{\infty} a_{0}(t) a_{0}(t-\tau) \cos \left[\theta_{m}(t)\right] \\
& \cdot e^{-i \omega \tau}\left\{\mu_{m, n} \cos \left[\theta_{m}(t-\tau)\right]-\cos \left[\theta_{n}(t-\tau)\right]\right\} d t d \tau \\
& =0
\end{aligned}
$$

When $\forall \tau \in(-\infty, \infty), \mu_{m, n}(\omega) \cos \left[\theta_{m}(t-\tau)\right]=\cos \left[\theta_{n}(t-\right.$ $\tau$ )], (A.6) is valid. Herein, $\tau$ is set to be 0 and then (A.8) can be expressed as

$$
\begin{aligned}
& \mu_{m, n}(\omega) \cos \left[\theta_{m}(t)\right]=\cos \left[\theta_{n}(t)\right] \\
& \theta_{n}(t)=\arccos \left[\mu_{m, n}(\omega) \cos \left[\theta_{m}(t)\right]\right]
\end{aligned}
$$

\section{Conflicts of Interest}

The authors declare no conflicts of interest. 


\section{Acknowledgments}

Financial support for the project from the National Key Research and Development Program of China (no. 2016YFC0800206), the National Natural Science Foundation of China (no. 51378234 and no. 51678465), and the Fundamental Research Funds for the Central Universities (no. 2015MS060) is acknowledged.

\section{References}

[1] A. Hindy and M. Novak, "Pipeline response to random ground motion," Journal of Engineering Mechanics ASCE, vol. 106, no. 2, pp. 339-360, 1980.

[2] W. L. Liu, X. G. Wu, L. M. Zhang, J. Zheng, and J. Teng, "Global sensitivity analysis of tunnel-induced building movements by a precise metamodel," Journal of Computing in Civil Engineering, vol. 31, no. 5, p. 04017037, 2017.

[3] A. S. Nazmy and A. M. Abdel-Ghaffar, "Effects of ground motion spatial variability on the response of cable-stayed bridges," Earthquake Engineering \& Structural Dynamics, vol. 21, no. 1, pp. 1-20, 1992.

[4] R. S. Harichandran, A. Hawwari, and B. N. Sweidan, "Response of long-span bridges to spatially varying ground motion a," Journal of Structural Engineering, vol. 122, no. 5, pp. 476-484, 1996.

[5] M.-T. Chen and R. S. Harichandran, "Response of an earth dam to spatially varying earthquake ground motion," Journal of Engineering Mechanics, vol. 127, no. 9, pp. 932-939, 2001.

[6] A. A. Dumanogluid and K. Soyluk, "A stochastic analysis of long span structures subjected to spatially varying ground motions including the site-response effect," Engineering Structures, vol. 25, no. 10, pp. 1301-1310, 2003.

[7] K. Soyluk, "Comparison of random vibration methods for multi-support seismic excitation analysis of long-span bridges," Engineering Structures, vol. 26, no. 11, pp. 1573-1583, 2004.

[8] M. Shinozuka and G. Deodatis, "Stochastic process models for earthquake ground motion," Probabilistic Engineering Mechanics, vol. 3, no. 3, pp. 114-123, 1988.

[9] A. Zerva, "Seismic ground motion simulations from a class of spatial variability models," Earthquake Engineering \& Structural Dynamics, vol. 21, no. 4, pp. 351-361, 1992.

[10] A. Zerva and M. Shinozuka, "Stochastic differential ground motion," Structural Safety, vol. 10, no. 1-3, pp. 129-143, 1991.

[11] G. Deodatis, "Non-stationary stochastic vector processes: seismic ground motion applications," Probabilistic Engineering Mechanics, vol. 11, no. 3, pp. 149-168, 1996.

[12] A. A. Shama, "Simplified procedure for simulating spatially correlated earthquake ground motions," Engineering Structures, vol. 29, no. 2, pp. 248-258, 2007.

[13] Y.-F. Gao, Y.-X. Wu, and B. Li, "Simplified method for simulation of ergodic spatially correlated seismic ground motion," Applied Mathematics and Mechanics. English Edition, vol. 32, no. 10, pp. 1297-1314, 2011.

[14] Y. Wu, Y. Gao, D. Li, C. Xu, and A. H. Mahfouz, "Study of the approximate approaches to the POD based spectral representation method," Science China Technological Sciences, vol. 56, no. 4, pp. 970-979, 2013.

[15] M. Shrikhande and V. K. Gupta, "Synthesizing ensembles of spatially correlated accelerograms," Journal of Engineering Mechanics, vol. 124, no. 11, pp. 1185-1192, 1998.
[16] S. Rezaeian and A. Der Kiureghian, "A stochastic ground motion model with separable temporal and spectral nonstationarities," Earthquake Engineering and Structural Dynamics, vol. 37, no. 13, pp. 1565-1584, 2008.

[17] Y. Ohsaki, "On the significance of phase content in earthquake ground motions," Earthquake Engineering \& Structural Dynamics, vol. 7, no. 5, pp. 427-439, 1979.

[18] Zhu Y. and Feng Q. M., "Digital characteristics of phase difference spectrum distribution of earthquake accelerogram," Earthquake Engineering \& Engineering Vibration, vol. 12, no. 1, pp. 37-44, 1992.

[19] Zhu Y. and Feng Q. M., "Distribution characteristic of phase difference spectrum and artificial accelerogram," Earthquake Engineering \& Engineering Vibration, vol. 13, no. 2, pp. 30-37, 1993.

[20] M. B. Priestley, SpEctral Analysis and Time Series, Academic Press, 1981.

[21] K. Sarkar and V. K. Gupta, "Wavelet-based simulation of spatially correlated and spectrum-compatible accelerograms," in Proceedings of the national symposium on structural dynamics, random vibrations earthquake engineering (NSSD '05), pp. 69-78, Department of Civil Engineering, Indian Institute of Science, Bangalore, 2005.

[22] P. Cacciola and G. Deodatis, "A method for generating fully non-stationary and spectrum-compatible ground motion vector processes," Soil Dynamics and Earthquake Engineering, vol. 31, no. 3, pp. 351-360, 2011.

[23] T. Kubo and J. Penzien, "Simulation of three-dimensional strong ground motions along principal axes, San Fernando earthquake," Earthquake Engineering \& Structural Dynamics, vol. 7, no. 3, pp. 279-294, 1979.

[24] Y. K. Lin and Y. Yong, "Evolutionary Kanai-Tajimi earthquake models," Journal of Engineering Mechanics, vol. 113, no. 8, pp. 1119-1137, 1987.

[25] A. Der Kiureghian and J. Crempien, "An evolutionary model for earthquake ground motion," Structural Safety, vol. 6, no. 2, pp. 235-246, 1989.

[26] J. P. Conte, K. S. Pister, and S. A. Mahin, "Nonstationary ARMA modeling of seismic motions," Soil Dynamics and Earthquake Engineering, vol. 11, no. 7, pp. 411-426, 1992.

[27] L. Hu, Y. L. Xu, and Y. Zheng, "Conditional simulation of spatially variable seismic ground motions based on evolutionary spectra," Earthquake Engineering and Structural Dynamics, vol. 41, no. 15, pp. 2125-2139, 2012.

[28] Y. Wu, Y. Gao, and D. Li, "Error assessment of multivariate random processes simulated by a conditional-simulation method," Journal of Engineering Mechanics, vol. 141, no. 5, Article ID 04014155, 2015.

[29] L. Cohen, Time-Frequency Analysis: Theory and Applications, Prentice-Hall, Inc, Englewood Cliffs, New Jersey, 1995.

[30] J. S. Bendat and A. G. Piersol, Random Data: Analysis and Measurement Procedures, John \& Wileys, New York, NY, USA, 1986.

[31] C.-H. Loh and S.-G. Lin, "Directionality and simulation in spatial variation of seismic waves," Engineering Structures, vol. 12, no. 2, pp. 134-143, 1990.

[32] Q. M. Feng and Y. X. Hu, "Spatial Correlation of Earthquake Motion and Its Effect on Structural Response, Bilateral Workshop on Earthquake Engineering, Beijing," 1982.

[33] C. Loh and Y. Yeh, "Spatial variation and stochastic modelling of seismic differential ground movement," Earthquake Engineering \& Structural Dynamics, vol. 16, no. 4, pp. 583-596, 1988. 
[34] H. Hao, C. S. Oliveira, and J. Penzien, "Multiple-station ground motion processing and simulation based on smart-1 array data," Nuclear Engineering and Design, vol. 111, no. 3, pp. 293-310, 1989.

[35] R. S. Harichandran and E. H. Vanmarcke, "Stochastic variation of earthquake ground motion in space and time," Journal of Engineering Mechanics, vol. 112, no. 2, pp. 154-174, 1986.

[36] K. Sobczyk, StochasTic Wave Propagation, Kluwer Academic Publishers, Netherlands, 1991.

[37] K. Bi and H. Hao, "Modelling and simulation of spatially varying earthquake ground motions at sites with varying conditions," Probabilistic Engineering Mechanics, vol. 29, pp. 92-104, 2012.

[38] H. Hao, EffEcts of Spatial Variation of Ground Motions on Large Multiple Supported Structures UCB/EERC-89-06, University of California, Berkeley, CA, USA, 1989. 


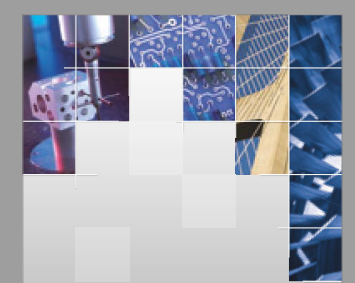

\section{Enfincering}
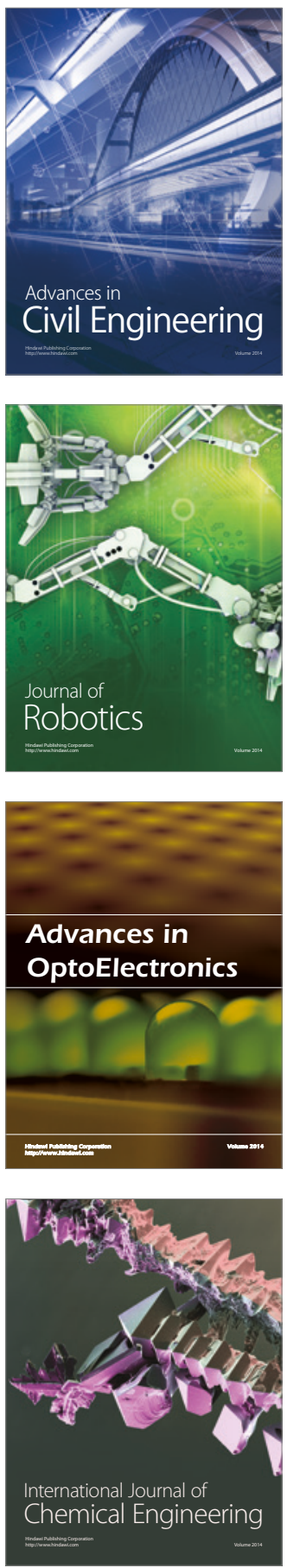

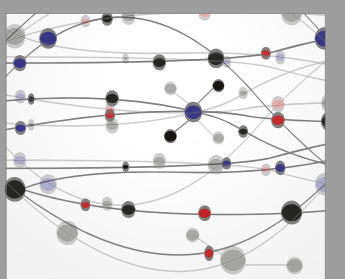

The Scientific World Journal

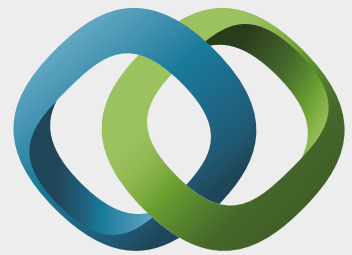

\section{Hindawi}

Submit your manuscripts at

https://www.hindawi.com
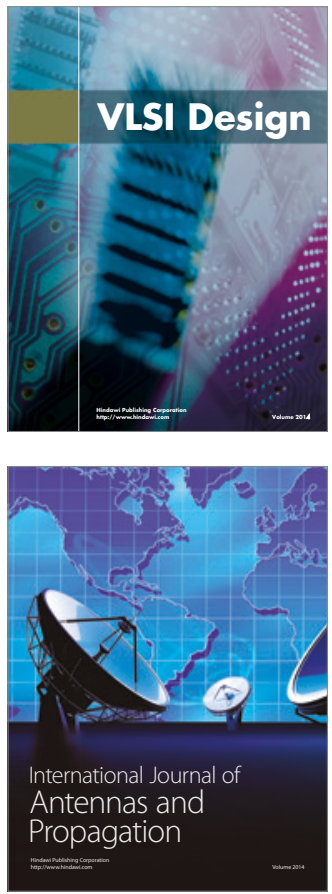

\section{Rotating}

Machinery
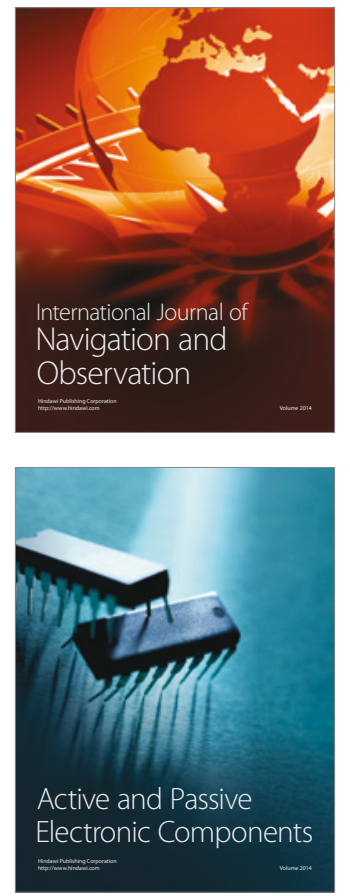
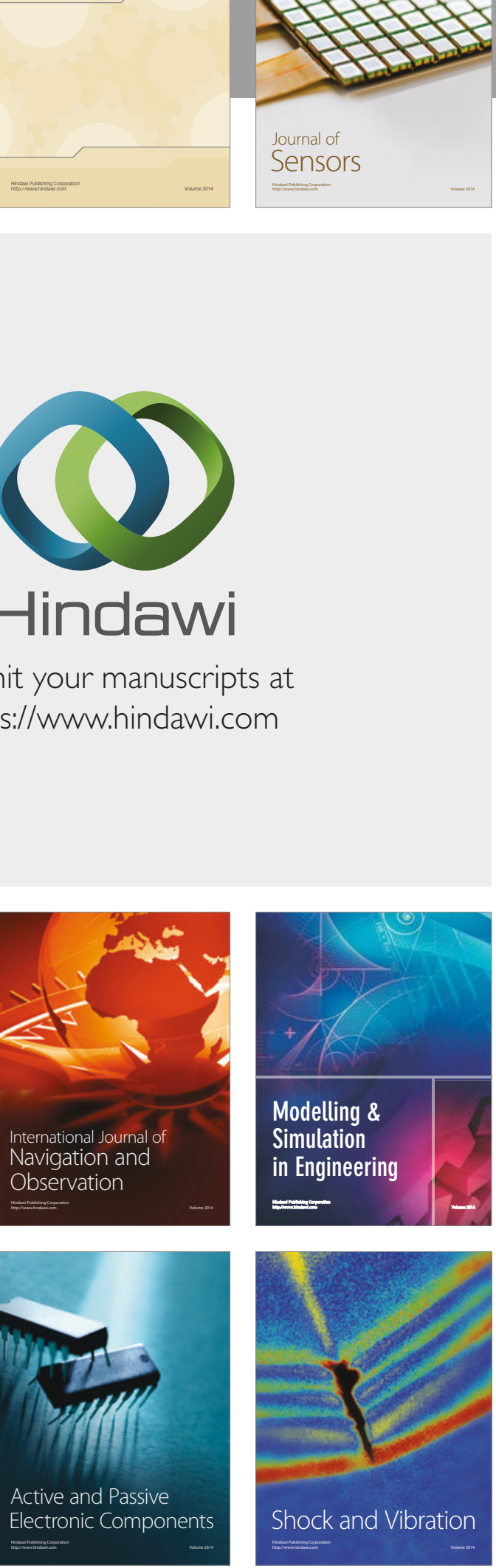
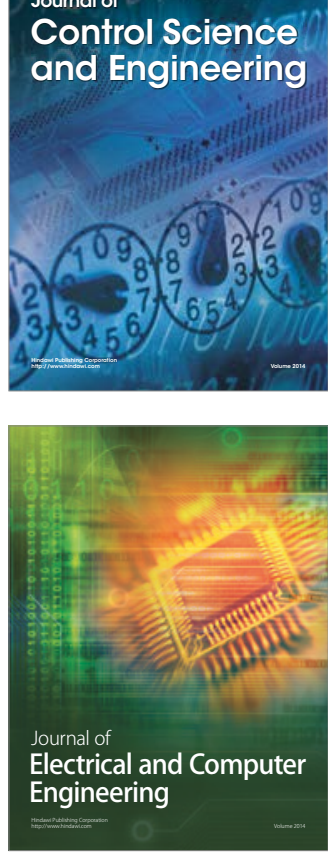

Distributed

Journal of

Control Science

and Engineering
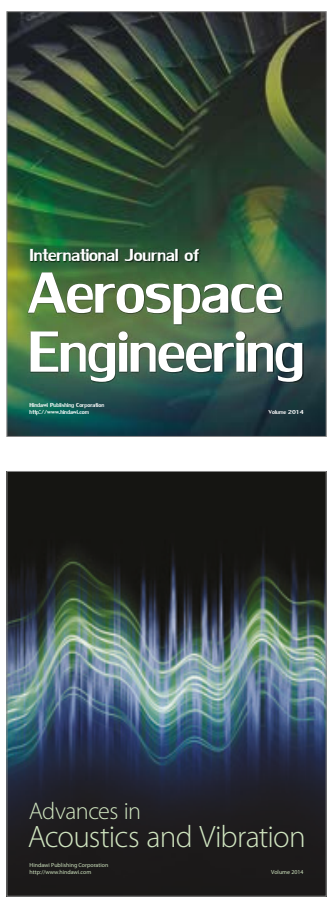

Sensor Networks 